\title{
Anthropometric parameters and their associations with cardio-metabolic risk in Chinese working population
}

Xiaojun Ouyang ${ }^{1,2}$, Qinlin Lou ${ }^{1,2}$, Liubao Gu ${ }^{1,2}$, Gary T Ko ${ }^{3}$, Yongzhen Mo ${ }^{1,2}$, Haidi Wu $u^{1,2}$ and Rongwen Bian ${ }^{1,2^{*}}$

\begin{abstract}
Background: There remains controversy regarding which of the anthropometric indicators best defines obesity. In this study, we compared the efficacy of using body mass index (BMI), waist circumference (WC) and waist-to-hip ratio (WHR) in the diagnosis of obesity and assessed their associations with diabetes, hypertension, and dyslipidemia in an urban working population in China.
\end{abstract}

Methods: Anthropometric measurements, blood pressure, plasma lipids, fasting and 2-hour plasma glucose (PG) levels by a 75 gram oral glucose tolerance test (OGTT) were obtained from 2603 working Chinese who had no history of cardiovascular diseases or diabetes. Cardio-metabolic risk factors including high blood pressure, dyslipidemia, and glucose intolerance were evaluated. The diagnoses of overweight and obesity were based on the WHO definitions with BMI for general obesity and WC and WHR for central obesity.

Results: Based on BMI, WC and WHR, there were 31.3\%, 16.6\%, 35.2\% of the studied subjects, respectively, being overweight and 2.0\%, 5.6\%, 9.2\% being obese. Among women but not men, more overweight and obese subjects were diagnosed using WHR and WC. The number of cardio-metabolic risks was higher by WC criterion than BMI and WHR in the whole group $(p<0.05)$ and female subjects $(p<0.01)$. Comparing the three anthropometric indexes predicting hypertension, hyperglycemia, dyslipidemia and multiple cardio-metabolic risks, for women, it was WC having the largest areas under ROC curves $(0.759,0.746,0.701$ and 0.773 respectively); while in men, it was WC for hypertension, WHR for hyperglycemia, BMI for dyslipidemia and WC for multiple cardio-metabolic risks (areas under ROC curves were 0.658, 0.686, 0.618 and 0.695 respectively).

Conclusions: Among Chinese working population, the need of lower cutoff values to define overweight and obesity were observed. Central obesity indicator (WC) is the preferred measure to predict the presence of cardio-metabolic risk in Chinese female subjects.

Keywords: Body mass index, Waist circumference, Waist-to-hip ratio, Obesity, Cardio-metabolic risks

\section{Introduction}

The increasing prevalence of obesity is a major public health problem worldwide. Wu et al. showed that there were $14.7 \%$ of Chinese being overweight (body mass index, BMI $25.0-29.9 \mathrm{~kg} / \mathrm{m}^{2}$ ) and another $2.6 \%$ being obese (BMI $\geq 30.0 \mathrm{~kg} / \mathrm{m}^{2}$ ) [1]. Obesity is a major independent risk factor for metabolic disorders, such as diabetes, hypertension,

\footnotetext{
*Correspondence: bianrw@126.com

'Diabetes Care and Research Center, Jiangsu Province Institute of Geriatrics, 30 Luojia Road, Nanjing 210024, China

${ }^{2}$ Department of Endocrinology and Metabolism, Jiangsu Province Institute of Geriatrics, 30 Luojia Road, Nanjing 210024, China

Full list of author information is available at the end of the article
}

insulin resistance and dyslipidemia. Their adverse effects on physical and social functioning and quality of life were also well documented $[2,3]$.

Recently, many studies had been using different definitions to classify obesity for Chinese, such as BMI $\geq 25$ to $<27.5 \mathrm{~kg} / \mathrm{m}^{2}$ as overweight and a BMI $\geq 27.5 \mathrm{~kg} / \mathrm{m}^{2}$ as general obesity [4], and a waist circumference (WC) $\geq 90 \mathrm{~cm}$ in men or $\mathrm{WC} \geq 80 \mathrm{~cm}$ in women as abdominal obesity [5], while local experts in Mainland China adopted a BMI $\geq 24$ to $<28 \mathrm{~kg} / \mathrm{m}^{2}$ as overweight and BMI $\geq 28 \mathrm{~kg} / \mathrm{m}^{2}$ as general obesity, and WC $\geq 85 \mathrm{~cm}$ for men and $\geq 80 \mathrm{~cm}$ for women as abdominal obesity [6]. 
To delineate obesity, various anthropometric measures have been proposed such as BMI, WC and waist-to-hip ratio (WHR). However, controversy still exists regarding which of these anthropometric indicators best defines obesity. Their relationships with cardio-metabolic risk also deserve further exploration. The aim of the present study is to compare the efficacy of BMI, WC and WHR in the diagnosis of obesity in a Chinese working population. We also attempted to assess their respective associations with diabetes, hypertension, and dyslipidemia by gender.

\section{Research design and methods}

We recruited 2603 subjects in Nanjing, an urban city of China with a population of 5.5 million. The study was conducted in the period between October 2003 and March 2005 (details of study procedure had been published previously) [7]. The survey was approved by Jiangsu Province Health Administrative Department and Ethics Committee. Every subject conxsented to participate in the study.

We measured body height, body weight, WC, Hip circumference with subjects in light clothing without shoes. Fat mass $(\mathrm{kg})$ and body fat percent $(\mathrm{BF} \%)$ were assessed with bioelectrical impedance equipment (TANITA, TBF300, France). The equation for BF\% used by this model of Tanita was developed by Brozek [8]:

$$
\mathrm{BF} \%=(4.57 / \text { body density }-4.142)^{*} 100
$$

Venous blood was collected from the ante-cubital vein after a 12-hour overnight fast. A 75 gram anhydrous glucose load oral glucose tolerance test (OGTT) was performed after fasting blood samples were collected. Blood for glucose assay was containing sodium fluoride, and fasting plasma glucose (FPG) and 2-hour plasma glucose (2hPG) levels were determined by the glucose-oxidase method. Serum total cholesterol (TC), high-density lipoprotein cholesterol (HDL-C), and triglyceride (TG) concentrations were determined enzymatically. Low-density lipoprotein cholesterol (LDL-C) was calculated using the Friedewald's formula [9]. Serum fasting insulin (FINS) and 2-hour post-OGTT insulin (2hINS) levels were measured by radioimmunoassay (RIA) with BNIBT kits (North Institute of Biological Technology, Beijing, China), of which the intra-assay coefficient of variation was below $10 \%$ and the inter-assay coefficient of variation was below $15 \%$.

Homeostasis model assessment of insulin resistance (HOMA-IR), an index which represents insulin resistance, was calculated according to the following formula [10]:

$$
\text { HOMA-IR }=[\text { FINS }(\mu \mathrm{U} / \mathrm{ml}) \times \text { FPG }(\mathrm{mmol} / \mathrm{L})] / 22.5
$$

High HOMA-IR was defined as HOMA-IR $\geq 2.69[11,12]$. The homeostasis model assessment of $\beta$-cell function (HOMA- $\beta$ ) was used to evaluate basal insulin secretion. This was calculated as:
HOMA $-\beta=[\operatorname{FINS}(\mu \mathrm{U} / \mathrm{ml}) \times 20] /[\mathrm{FPG}(\mathrm{mmol} / \mathrm{L})-3.5]$

Low HOMA- $\beta$ was defined as HOMA- $\beta \leq 111.2$ [13].

\section{Definitions}

Hypertension was defined as systolic and/or diastolic blood pressure (BP) $\geq 140 / 90 \mathrm{mmHg}$ and/or current use of antihypertensive agents. Hyperglycemia was defined as FPG $\geq 5.6 \mathrm{mmol} / \mathrm{L}$ and/or $2 \mathrm{hPG} \geq 7.8 \mathrm{mmol} / \mathrm{L}$ or with known diabetes history. Dyslipidmia was defined as having 1 or more of the following: TC $\geq 5.18 \mathrm{mmol} / \mathrm{L}$, HDL-C $<1.04 \mathrm{mmol} / \mathrm{L}, \mathrm{LDL}-\mathrm{C} \geq 3.37 \mathrm{mmol} / \mathrm{L}$ and TG $\geq 1.70 \mathrm{mmol} /$ $\mathrm{L}$ [14]. The presence of 2 or more of the above three cardiometabolic risk factors (i.e. hypertension, hyperglycemia, dyslipidemia) was defined as having "multiple metabolic risks".

The diagnoses of overweight and obese were based on World Health Organization (WHO) classification [15]. Those with a BMI of $25.0-29.9 \mathrm{~kg} / \mathrm{m}^{2}$ were classified as overweight, whilst those with a BMI $\geq 30.0 \mathrm{~kg} / \mathrm{m}^{2}$ were classified as obese. Men with a WC of 94-101.9 cm and women of $80-87.9 \mathrm{~cm}$ were classified as overweight, whilst men with a WC $\geq 102.0 \mathrm{~cm}$ and women $\geq 88.0 \mathrm{~cm}$ were classified as obese. Men with a WHR of $0.90-0.99$ and women of 0.80-0.84 were classified as overweight, whilst men and women with a WHR $\geq 1.00$ and $\geq 0.85$ were classified as obese, respectively [15].

\section{Statistical analysis}

Statistical analysis was performed using the SPSS (version 15.0) software for Windows. Continuous variables were presented as mean $\pm \mathrm{SD}$ and categorical data as number (\%). Difference in means between groups was tested using oneway analysis of variance (ANOVA) and Chi-square $\left(\chi^{2}\right)$ test where appropriate. A $p$-value $<0.05$ (two-tailed) was considered to be statistically significant. The univariate analysis and logistic regression analysis were conducted to compare the differences among the 3 anthropometric indexes in their relationships with hypertension, hyperglycemia and dyslipidemia. Receiver operating characteristic (ROC) curve analyses and area-under-curve (AUC) were plotted and compared with regard to their associations with various metabolic risk factors, and were used to determine the optimal values for BMI, WC and WHR in diagnosing obesity by gender. The maximal Youden Index (YI), defined as the sum of specificity and sensitivity minus one and its associated optimal cutoff point on the ROC curves was also estimated.

\section{Results}

Of the 2603 subjects, 1590 (61.1\%) were men and 1013 (38.9\%) were women. Their mean age was $47.3 \pm 11.6$ years (median 46 years, range 23 to 79 years). Compared to women, men had higher BMI, WC, WHR, BP, PG, TG, insulin levels, HOMA-IR, and more smokers, hypertension, hyperglycemia and dyslipidemia, but lower HDL-C level, 
fat mass and BF\% (Table 1). There were $42 \%$ subjects having a high HOMA-IR level and one quarter of the whole study group had a low HOMA- $\beta$ level. Among the 1013 women, $365(36.0 \%)$ were menopausal. As compared to pre-menopausal women, those with menopause had worse cardio-metabolic profiles (higher anthropometric parameters, fat mass, BF\%, BP, lipid profiles, glycemic indexes, higher Homa-IR and lower Homa- $\beta$ ) (detailed data not shown).

According to BMI, WC and WHR criteria respectively, $31.3 \%(\mathrm{n}=816), 16.6 \%$ (431), 35.2\% (917) subjects had overweight and 2.0\% (52), 5.6\% (147), 9.2\% (239) subjects had obesity. Among women but not men, more overweight and obese subjects were diagnosed by WHR and

Table 1 Clinical and biochemical characteristics of the 2603 Chinese subjects

\begin{tabular}{|c|c|c|c|c|}
\hline & Total $(n=2603)$ & Men $(n=1590)$ & Women $(n=1013)$ & $p$-value ${ }^{*}$ \\
\hline Age (years) & $47.3 \pm 11.6$ & $47.6 \pm 11.6$ & $47.2 \pm 11.6$ & 0.373 \\
\hline $\mathrm{BMI}\left(\mathrm{kg} / \mathrm{m}^{2}\right)$ & $23.7 \pm 2.9$ & $24.4 \pm 2.6$ & $22.6 \pm 3.0$ & 0.000 \\
\hline$W C(\mathrm{~cm})$ & $82.5 \pm 9.2$ & $86.3 \pm 7.3$ & $76.4 \pm 8.6$ & 0.000 \\
\hline WHR & $0.85 \pm 0.06$ & $0.89 \pm 0.05$ & $0.81 \pm 0.05$ & 0.000 \\
\hline Fat mass (kg) & $26.1 \pm 6.6$ & $24.5 \pm 11.6$ & $28.5 \pm 7.3$ & 0.000 \\
\hline $\mathrm{BF} \%$ & $18.0 \pm 5.7$ & $17.7 \pm 5.8$ & $18.2 \pm 5.6$ & 0.044 \\
\hline $\mathrm{SBP}(\mathrm{mmHg})$ & $119.9 \pm 16.2$ & $122.8 \pm 15.5$ & $115.4 \pm 16.3$ & 0.000 \\
\hline $\mathrm{DBP}(\mathrm{mmHg})$ & $78.0 \pm 10.1$ & $80.3 \pm 9.9$ & $74.4 \pm 9.3$ & 0.000 \\
\hline $\mathrm{TC}(\mathrm{mmol} / \mathrm{L})$ & $4.99 \pm 0.86$ & $4.98 \pm 0.84$ & $5.02 \pm 0.89$ & 0.213 \\
\hline $\mathrm{HDL}-\mathrm{C}(\mathrm{mmol} / \mathrm{L})$ & $1.41 \pm 0.29$ & $1.35 \pm 0.29$ & $1.49 \pm 0.28$ & 0.000 \\
\hline $\mathrm{LDL}-\mathrm{C}(\mathrm{mmol} / \mathrm{L})$ & $2.96 \pm 0.68$ & $2.95 \pm 0.67$ & $2.98 \pm 0.70$ & 0.239 \\
\hline $\mathrm{TG}(\mathrm{mmol} / \mathrm{L})$ & $1.60 \pm 1.11$ & $1.82 \pm 1.17$ & $1.24 \pm 0.89$ & 0.000 \\
\hline Fasting PG (mmol/L) & $5.0 \pm 0.9$ & $5.1 \pm 1.0$ & $4.9 \pm 0.8$ & 0.000 \\
\hline OGTT 2 hr PG (mmol/L) & $6.4 \pm 2.4$ & $6.6 \pm 2.5$ & $6.3 \pm 2.2$ & 0.003 \\
\hline Fasting serum Insulin (ulU/ml) & $12.7 \pm 7.1$ & $13.0 \pm 7.3$ & $12.3 \pm 6.9$ & 0.010 \\
\hline OGTT 2 hr serum Insulin (ulU/ml) & $64.2 \pm 49.1$ & $65.9 \pm 49.2$ & $61.6 \pm 48.6$ & 0.030 \\
\hline HOMA-IR & $2.85 \pm 1.85$ & $2.98 \pm 1.97$ & $2.71 \pm 1.76$ & 0.000 \\
\hline High HOMA-IR (\%) & 42.0 & 45.3 & 36.9 & 0.004 \\
\hline Homa- $\beta$ & $204.1 \pm 177.0$ & $202.1 \pm 187.5$ & $206.1 \pm 157.3$ & 0.575 \\
\hline Low HOMA- $\beta$ (\%) & 25.3 & 27.1 & 22.5 & 0.009 \\
\hline Smoking (\%) & 31.5 & 50.2 & 2.0 & 0.000 \\
\hline Hypertension (\%) & 30.9 & 35.8 & 23.4 & 0.000 \\
\hline Newly diagnosed (\%) & 7.8 & 9.8 & 4.5 & 0.000 \\
\hline Known hypertensive (\%) & 23.1 & 26.0 & 18.9 & 0.000 \\
\hline Hyperglycemia (\%) & 19.3 & 25.1 & 19.5 & 0.001 \\
\hline Isolated IFG & 1.2 & 1.7 & 0.6 & 0.012 \\
\hline Isolated IGT & 10.1 & 10.1 & 10.1 & 1.0 \\
\hline Combined IFG/IGT & 2.1 & 2.7 & 1.3 & 0.013 \\
\hline Diabetes mellitus & 5.9 & 6.5 & 4.8 & 0.000 \\
\hline Dyslipidemia (\%) & 59.6 & 65.6 & 50.0 & 0.000 \\
\hline $\mathrm{TC} \geq 5.18 \mathrm{mmol} / \mathrm{L}$ & 40.2 & 39.5 & 41.3 & 0.369 \\
\hline $\mathrm{HDL}-\mathrm{C}<1.04 \mathrm{mmol} / \mathrm{L}$ & 9.0 & 12.3 & 3.9 & 0.000 \\
\hline $\mathrm{LDL}-\mathrm{C} \geq 3.37 \mathrm{mmol} / \mathrm{L}$ & 25.5 & 24.8 & 26.8 & 0.271 \\
\hline $\mathrm{TG} \geq 1.70 \mathrm{mmol} / \mathrm{L}$ & 32.2 & 41.6 & 17.2 & 0.000 \\
\hline
\end{tabular}

* $p$-value:comparing men and women.

$\mathrm{BMI}$, body mass index; WC, waist circumference; WHR, waist-to-hip ratio; BF\%, body fat percent; SBP, systolic blood pressure; DBP, diastolic blood pressure; TC, total cholesterol; HDL-C and LDL-C, high- and low-density lipoprotein cholesterol; TG, triglyceride; OGT, oral glucose tolerance test; PG, plasma glucose; IFG, impaired fasting glucose; IGT, impaired glucose tolerance; high HOMA-IR = HOMA-IR $\geq 2.69$; low HOMA- $\beta=\mathrm{HOMA}-\beta \leq 111.2$; isolated IFG $=$ fasting PG $\geq 6.1$ and $<7.0$ mmol/L and $2 \mathrm{~h}$ PG $<7.8 \mathrm{mmol} / \mathrm{L}$; isolated IGT = fasting PG $<6.1 \mathrm{mmol} / \mathrm{L}$ and $2 \mathrm{~h} \mathrm{PG} \geq 7.8$ and $<11.1 \mathrm{mmol} / \mathrm{L}$; combined IFG/IGT $=$ fasting PG $\geq 6.1$ and $<7.0 \mathrm{mmol} / \mathrm{L}$ and/or $2 \mathrm{~h} P G \geq 7.8$ and $<11.1 \mathrm{mmol} / \mathrm{L}$; diabetes mellitus = fasting $P G \geq 7.0 \mathrm{mmol} / \mathrm{L}$ and $/$ or $2 \mathrm{~h} P G \geq 11.1 \mathrm{mmol} / \mathrm{L}$. 
WC. In the obese group, $78.2 \%$ and $94.1 \%$ were women by WC and WHR criteria, but only $38.5 \%$ when using BMI.

Using WC criteria, both obese men and women had about 2 cardio-metabolic risk factors. The number of cardio-metabolic risk factors was higher by WC criteria than BMI and WHR in total $(1.99 \pm 0.93$ vs. $1.85 \pm 0.85$ vs. $1.62 \pm 0.98$, respectively, $p<0.05)$ and female subjects $(1.99 \pm 0.93$ vs. $1.95 \pm 0.76$ vs. $1.61 \pm 0.97$, respectively, $p$ $<0.01$ ), but no difference was found in male subjects or between BMI and WHR criteria ( $2.0 \pm 0.95$ vs. $1.78 \pm$ 0.91 vs. $1.86 \pm 1.10$, respectively, $p$-value: NS).

The percentage of subjects having cardio-metabolic risk factors by the three anthropometric measures increased as with obesity worsened. According to BMI, WC and WHR criteria, 23.4\%, 26.3\% and 23.6\% normal subjects as well as $63.5 \%, 67.3 \%$ and $51.9 \%$ obese subjects had multiple ( 2 or more) cardio-metabolic risk factors, respectively.

With logistic regression analysis, the odd-ratio (OR) of hypertension, hyperglycemia, and dyslipidemia increased as the anthropometric parameters increased ( $p$-values all $<0.01)$. After adjustment for age and smoking in obese women, WC had the highest OR in predicting hypertension and hyperglycemia, while WHR had the highest OR to predict dyslipidemia.. Among obese men, WC for hypertension and WHR for hyperglycemia had the highest OR (Table 2). All 3 anthropometric parameters lost their statistical significance in predicting dyslipidemia in obese male subjects. But among overweight men, WC had the highest OR.

Table 3 shows the ROC curves to determine the appropriate BMI, WC and WHR values for detecting the presence of various metabolic risks in males and females respectively. The cutoff value of BMI to predict multiple metabolic risks were $24.6 \mathrm{~kg} / \mathrm{m}^{2}$ and $22.6 \mathrm{~kg} / \mathrm{m}^{2}$ in man and women, respectively. Those of WC and WHR were $85.5 \mathrm{~cm}$ and $77.5 \mathrm{~cm}, 0.89$ and 0.83 in men and women, respectively. In women, the largest AUC were detected by WC (respectively $0.759,0.746,0.701$ and 0.773 for hypertension, hyperglycemia, dyslipidemia and multiple metabolic risks). While in men, the corresponding figures were by WC for hypertension, WHR for hyperglycemia, BMI for dyslipidemia and WC for multiple metabolic risks (AUC $=0.658,0.686,0.618$ and 0.695 respectively with their 95\% CIs overlapping with each other).

\section{Discussion}

To ensure comparability with other studies, our study selected the criteria recommended by WHO classifications [4]. In this study, the prevalence of overweight/ obesity was $31.3 \% / 2.0 \%, 16.6 \% / 5.6 \%, 35.2 \% / 9.2 \%$ by BMI, WC and WHR respectively. These results exhibited lower prevalence of overweight and obesity than those seen in Western countries [16,17].
In agreement with other South Asian and Chinese data $[18,19]$, our findings confirmed that quite a few subjects with normal weight were already associated with many cardio-metabolic risk factors and those with overweight or obesity, their associated risks were even higher. In other words, using a lower obesity cutoff value for Chinese population appears to be reasonable in a general health prevention point of view [20]. Nguyen et al. had suggested that the optimal BMI cutoff value being $23-24 \mathrm{~kg} / \mathrm{m}^{2}$ for Chinese [21]. In the present study with Chinese working population, the optimal BMI cutoff values to detect the presence of multiple metabolic risk factors were $24.6 \mathrm{~kg} / \mathrm{m}^{2}$ for men and $22.6 \mathrm{~kg} / \mathrm{m}^{2}$ for women, while the WC cutoff values were $85.5 \mathrm{~cm}$ for men and $77.5 \mathrm{~cm}$ for women. All these values were closely approximate to those being reported by many Japanese and Korean studies $[22,23]$, while slightly higher than those by studies in Hong Kong [24]. Actually, in the last international joint statement of diagnosing metabolic syndrome published in 2009, a population- and country-specific definition for elevated WC was highlighted [25]. Among Chinese and Asian, a WC cutoff of $85-90 \mathrm{~cm}$ for men and $80 \mathrm{~cm}$ for women were suggested to define abdominal obesity. These figures were similar to what we have found in this study.

More women were diagnosed using central obesity indexes (WC and WHR) than BMI, while men had similar obese prevalence by all 3 measures. Interestingly, we also found most centrally obese subjects were women. Similar findings were also obtained from a study in Iran that the prevalence of abdominal obesity was much higher in women (53.5\%) than in men (12.5\%) [26]. Hauner et al. also reported that women more often had an increased WC as compared to men [27]. All these findings suggested the WC and WHR criteria for central obesity in men may be too cautiously high. In accord to this, based on HOMA-IR level correlating to metabolic parameters among Japanese subjects, Kamezaki $\mathrm{F}$ et al. demonstrated that WC cutoff level should be reduced and more strictly managed [28].

It is well documented that WC more closely correlates with the abdominal visceral fat than either WHR or BMI. In agreement with our findings, most cross-sectional studies showed a stronger association of cardiovascular risk factors with central obesity (based on WC or WHR) than with general obesity (BMI) in Chinese as well as other ethnic populations [29-31]. The prospective AusDiab Study confirmed that abdominal obesity was associated with ORs between 2 and 5 for incident type 2 diabetes, dyslipidemia and hypertension at 5-year follow up [32].

Insulin resistance contributed largely to the underlying pathogenesis of hyperglycemia, hypertension and dyslipidemia, while central obesity has been closely linked to insulin resistance. Among Chinese teenagers, Yin et al. have shown that those with 3 or more cardiovascular 
Table 2 Multiple logistic regression analysis of the associations between BMI, WC, WHR and cardio-metabolic risks

\begin{tabular}{|c|c|c|c|c|c|c|c|c|c|c|}
\hline \multirow{2}{*}{\multicolumn{2}{|c|}{ OR $(95 \% \mathrm{Cl})$}} & \multicolumn{3}{|l|}{ Hypertension } & \multicolumn{3}{|l|}{ Hyperglycemia } & \multicolumn{3}{|l|}{ Dyslipidemia } \\
\hline & & \multirow[t]{2}{*}{ Crude } & \multirow[t]{2}{*}{ Adjusted for age } & \multirow[t]{2}{*}{$\begin{array}{l}\text { Adjusted for } \\
\text { age and smoking }\end{array}$} & \multirow[t]{2}{*}{ Crude } & \multirow[t]{2}{*}{ Adjusted for age } & \multirow[t]{2}{*}{$\begin{array}{l}\text { Adjusted for } \\
\text { age and smoking }\end{array}$} & \multirow[t]{2}{*}{ Crude } & \multirow[t]{2}{*}{ Adjusted for age } & $\begin{array}{l}\text { Adjusted for } \\
\text { age and smoking }\end{array}$ \\
\hline \multicolumn{3}{|c|}{ Men $(n=1590)$} & & & & & & & & \\
\hline \multirow[t]{2}{*}{ BMI } & overweight & * $1.86(1.46-2.35)$ & * $2.15(1.67-2.77)$ & * $2.62(2.08-3.30)$ & ${ }^{*} 1.42(1.07-1.89)$ & * $1.56(1.16-2.09)$ & * $2.15(1.65-2.79)$ & * $1.55(1.21-1.98)$ & * $1.54(1.21-1.97)$ & ${ }^{*} 1.82(1.45-2.28)$ \\
\hline & obese & $0.78(0.32-1.90)$ & $0.93(0.37-2.37)$ & $1.72(0.78-3.80)$ & * $2.77(1.16-6.63)$ & * $3.41(1.40-8.31)$ & * $6.33(2.92-13.72)$ & $1.99(0.73-5.47)$ & $1.99(0.72-5.47)$ & $2.26(0.96-5.30)$ \\
\hline \multirow[t]{2}{*}{ WC } & overweight & $1.28(0.91-1.79)$ & $1.14(0.80-1.62)$ & * $2.01(1.48-2.72)$ & $1.18(0.82-1.71)$ & $1.08(0.74-1.57)$ & * $2.32(1.69-3.20)$ & $1.27(0.87-1.87)$ & $1.27(0.87-1.87)$ & * $1.94(1.38-2.71)$ \\
\hline & obese & * $3.04(1.22-7.57)$ & $2.88(0.94-5.68)$ & * $4.20(1.86-9.47)$ & * $2.44(1.04-5.76)$ & $1.84(0.76-4.47)$ & * $6.30(2.89-13.70)$ & $1.08(0.41-2.84)$ & $1.08(0.41-2.84)$ & $1.88(0.83-4.25)$ \\
\hline \multirow[t]{2}{*}{ WHR } & overweight & * $1.48(1.16-1.88)$ & * $1.46(1.13-1.81)$ & * $2.01(1.60-2.53)$ & * $2.31(1.74-3.07)$ & * $2.33(1.75-3.11)$ & * $2.97(2.28-3.86)$ & * $1.31(1.03-1.68)$ & * $1.31(1.02-1.68)$ & * $1.64(1.31-2.05)$ \\
\hline & obese & $2.38(0.72-7.91)$ & $2.19(0.62-7.77)$ & $2.81(0.92-8.57)$ & * $6.68(2.03-22.00)$ & * $6.48(1.93-21.75)$ & * $8.09(2.68-24.37)$ & $1.02(0.30-3.50)$ & $1.02(0.30-3.50)$ & $1.50(0.47-4.85)$ \\
\hline \multicolumn{11}{|c|}{ Women $(n=1013)$} \\
\hline \multirow[t]{2}{*}{ BMl } & overweight & $1.32(0.84-2.10)$ & * $1.99(1.20-3.29)$ & * $3.12(2.14-4.14)$ & $0.73(0.43-1.24)$ & $0.97(0.55-1.70)$ & * $1.87(1.25-2.81)$ & $0.98(0.57-1.67)$ & $1.07(0.60-1.92)$ & $1.38(0.88-2.16)$ \\
\hline & obese & $1.33(0.40-4.42)$ & $2.26(0.58-8.83)$ & * 3.49 (1.16-10.50) & $1.15(0.34-3.96)$ & $1.70(0.45-6.40)$ & * $3.15(1.07-9.26)$ & $1.88(0.22-15.97)$ & $3.47(0.34-34.96)$ & $1.86(0.34-10.55)$ \\
\hline \multirow[t]{2}{*}{ WC } & overweight & * $2.79(1.74-4.47)$ & $1.37(0.82-2.28)$ & * $1.92(1.28-2.88)$ & * $2.27(1.33-3.88)$ & $1.27(0.73-2.23)$ & * $1.71(1.09-2.70)$ & * $2.51(1.48-4.23)$ & $1.39(0.77-2.52)$ & $1.53(0.98-2.40)$ \\
\hline & obese & * $7.24(3.67-14.31)$ & * $2.17(1.03-4.60)$ & * $3.95(2.35-6.63)$ & * $6.86(3.29-14.31)$ & ${ }^{*} 6.86(1.17-5.62)$ & * $3.34(1.97-5.68)$ & * 3.38 (1.42-8.03) & $1.07(0.39-2.93)$ & $1.48(0.74-2.97)$ \\
\hline \multirow[t]{2}{*}{ WHR } & overweight & 1.19 (0.80-1.77) & $0.96(0.63-1.48)$ & $1.16(0.76-1.76)$ & $1.10(0.69-1.78)$ & $0.95(0.58-1.55)$ & $0.88(0.54-1.44)$ & * $1.47(1.06-2.04)$ & $1.10(0.77-1.59)$ & $1.20(0.84-1.72)$ \\
\hline & obese & $1.18(0.72-1.95)$ & $1.10(0.66-1.85)$ & * $2.07(1.36-3.17)$ & * $1.94(1.13-3.33)$ & * $1.91(1.12-3.27)$ & * $2.44(1.53-3.87)$ & * $1.82(1.09-3.06)$ & $1.38(0.76-2.52)$ & * $1.64(1.03-2.64)$ \\
\hline
\end{tabular}

Normal as reference $(O R=1)$, ${ }^{*} p$-value $=$ statistically significant with $p<0.05$.

$\mathrm{Cl}$, confidence interval; OR, odds ratio; BMI, body mass index; WC, waist circumference; WHR, waist-to-hip ratio. 
Table 3 The cutoff values, sensitivity and specificity for cardio-metabolic risks by BMI, WC and WHR

\begin{tabular}{|c|c|c|c|c|c|c|c|c|c|c|c|c|}
\hline & \multicolumn{4}{|c|}{ BMI $\left(\mathrm{kg} / \mathrm{m}^{2}\right)$} & \multicolumn{4}{|c|}{ WC (cm) } & \multicolumn{4}{|l|}{ WHR } \\
\hline & Cutoff & Se (\%) & Sp (\%) & YI & Cutoff & Se (\%) & Sp (\%) & YI & Cutoff & Se (\%) & Sp (\%) & YI \\
\hline \multicolumn{13}{|l|}{ Men $(n=1590)$} \\
\hline Hypertension & 24.2 & 67.3 & 54.8 & 0.22 & 85.5 & 69.2 & 53.9 & 0.23 & 0.89 & 59.4 & 59.8 & 0.19 \\
\hline Hyperglycemia & 24.9 & 57.5 & 61.2 & 0.19 & 88.5 & 55.3 & 68.4 & 0.24 & 0.91 & 55.9 & 73 & 0.29 \\
\hline Dyslipidemia & 24.0 & 62.5 & 54.2 & 0.17 & 87.5 & 46.5 & 68.1 & 0.15 & 0.88 & 60.6 & 56.7 & 0.17 \\
\hline Multiple risk factors & 24.6 & 63.8 & 63.0 & 0.27 & 85.5 & 72.8 & 55.6 & 0.28 & 0.89 & 63.4 & 62.8 & 0.26 \\
\hline \multicolumn{13}{|l|}{ Women $(n=1013)$} \\
\hline Hypertension & 22.9 & 69.9 & 66.8 & 0.37 & 77.5 & 67.7 & 70.2 & 0.38 & 0.82 & 65.0 & 66.8 & 0.32 \\
\hline Hyperglycemia & 23.6 & 54.9 & 70.3 & 0.25 & 77.5 & 67.3 & 67.1 & 0.34 & 0.84 & 53.7 & 80.4 & 0.34 \\
\hline Dyslipidemia & 22.2 & 58.7 & 68.6 & 0.27 & 75.5 & 58.7 & 74.2 & 0.33 & 0.81 & 55.5 & 67.8 & 0.23 \\
\hline Multiple risk factors & 22.6 & 71.4 & 63.7 & 0.35 & 77.5 & 67.7 & 72.4 & 0.40 & 0.83 & 63.6 & 72.7 & 0.36 \\
\hline
\end{tabular}

BMI, body mass index; WC, waist circumference; WHR, waist-to-hip ratio, Se: Sensitivity, Sp: Specificity, YI: Youden Index.

risk factors or metabolic abnormalities as compared to those without risk factors had a 4-fold increase in HOMAIR and a mean difference in WC of $23 \mathrm{~cm}$ [33]. Among Canadians of different ethnicities, Chateau-Degat et al. have also demonstrated that those in the highest WC quartile had the highest HOMA-IR highlighting the importance of increased abdominal obesity on metabolic parameters [34]. Interestingly, they also showed that WC did not have a similar deleterious impact according to ethnicity suggesting the need for an ethnic-based definition.

Yet, some studies did not show consistently significant differences between measures of general and central obesity [35-37]. In the Decoda study, though diabetes had stronger association with waist-to-stature ratio (WSR) than BMI $(p=0.001)$ in men and a similar higher risk with WC and WSR than BMI (both $p<0.05$ ) in women, they also found that hypertension had stronger association with BMI than WHR in men $(p<0.001)$ and a highest risk with BMI than other parameters in women [38]. It is now widely accepted that, on the one hand, abdominal obesity is a main predictive factor of cardio-metabolic risk, while on the other hand, BMI, WC and WHR are all useful tools for assessing adiposity in clinical practice $[39,40]$.

The present study has its own limitations. This is a crosssectional epidemiological study with surrogate measures of general and central obesity instead of direct measure of body composition being used for analysis in the prediction of metabolic risks. In addition, our subjects came from a working population who might not be able to represent all the socioeconomic status of the general population. The biased nature of our sample was also expressed with more than $40 \%$ of our subjects having a high HOMA-IR level and up to a quarter of them having a low HOMA- $\beta$ level, suggesting a less favorable metabolic indices among our study subjects. In accord to this, high risk for cardiovascular disease and suboptimal health among working population has been reported both in Chinese and Caucasians [41,42].

\section{Conclusion}

In this study, the number of cardio-metabolic risk factors increased with the degree of obesity in our Chinese working population. The need for a lower cutoff values to define overweight and obesity were observed. Men have a higher prevalence of overweight or general obesity than women, whereas women have a higher prevalence of abdominal obesity than men. WC, being the most important central obesity indicator, is the preferred measure to predict the presence of cardio-metabolic risk in Chinese women. WC also provides important information in Chinese men on their cardio-metabolic risk while BMI supplements significantly.

\section{Abbreviations}

BMI: Body mass index; WC: Waist circumference; WHR: Waist-to-hip ratio; BP: Blood pressure; BF\%: Body fat percent (BF\%); OGTT: Oral glucose tolerance test; FPG: Fasting plasma glucose; 2hPG: 2-hour plasma glucose; TC: Total cholesterol; HDL-C: High-density lipoprotein cholesterol; TG: Triglyceride; LDL-C: Low-density lipoprotein cholesterol; FINS: Fasting insulin; 2hINS: 2-hour post-OGTT insulin; RIA: Radioimmunoassay; HOMA-IR: Homeostasis model assessment of insulin resistance; HOMA- $\beta$ : Homeostasis model assessment of $\beta$-cell function; WHO: World Health Organization; ANOVA: One-way analysis of variance; ROC: Receiver operating characteristic; AUC: Area-under-curve; OR: Odd-ratio; WSR: Waist-to-stature ratio.

\section{Competing interests}

The authors declare that they have no competing interests.

\section{Authors' contributions}

$X \mathrm{O}, \mathrm{QL}$ and $\mathrm{RB}$ conceived and designed the study. $\mathrm{XO}, \mathrm{QL}, \mathrm{LG}, \mathrm{YM}, \mathrm{HW}$ and $\mathrm{RB}$ conducted the study. $\mathrm{XO}$ analyzed the data. $\mathrm{XO}, \mathrm{GK}$ and RB wrote the manuscript. All authors read and approved the final manuscript.

\section{Author details}

${ }^{1}$ Diabetes Care and Research Center, Jiangsu Province Institute of Geriatrics, 30 Luojia Road, Nanjing 210024, China. ${ }^{2}$ Department of Endocrinology and Metabolism, Jiangsu Province Institute of Geriatrics, 30 Luojia Road, Nanjing 210024, China. ${ }^{3}$ Department of Medicine and Therapeutics, Prince of Wales Hospital, the Chinese University of Hong Kong, Hong Kong, China.

Received: 10 September 2014 Accepted: 9 April 2015

Published online: 24 April 2015 


\section{References}

1. Wu Y. Overweight and obesity in China. BMJ. 2006;333(7564):362-3.

2. Cameron AJ, Magliano DJ, Soderberg S. A systematic review of the impact of including both waist and hip circumference in risk models for cardiovascular diseases, diabetes and mortality. Obes Rev. 2013;14(1):86-94.

3. Visscher $\mathrm{TL}$, Seidell JC. The public health impact of obesity. Annu Rev Public Health. 2001;22:355-75

4. WHO. World Health Organization (WHO) Expert consultation: appropriate body-mass index for Asian populations and its implications for policy and intervention strategies. Lancet. 2004:363(9403):157-63.

5. Alberti KG, Zimmet P, Shaw J. The metabolic syndrome-a new worldwide definition. Lancet. 2005;366(9491):1059-62

6. Zhou BF. Predictive values of body mass index and waist circumference for risk factors of certain related diseases in Chinese adults-study on optimal cut-off points of body mass index and waist circumference in Chinese adults. Biomed Environ Sci. 2002;15(1):83-96.

7. Ouyang X, Lou Q, Gu L, Mo Y, Nan JH, Kong AP, et al. Cardiovascular disease risk factors are highly prevalent in the office-working population of Nanjing in China. Int J Cardiol. 2012;155(2):212-6.

8. Brozek J, Grande F, Anderson JT, Keys A. Densitometric analysis of body composition: revision of some quantitative assumptions. Ann N Y Acad Sci. 1963;110:113-40

9. Friedewald WT, Levy RI, Fredrickson DS. Estimation of the concentration of low-density lipoprotein cholesterol in plasma, without use of the preparative ultracentrifuge. Clin Chem. 1972;18(6):499-502

10. Matthews DR, Hosker JP, Rudenski AS, Naylor BA, Treacher DF, Turner RC. Homeostasis model assessment: insulin resistance and beta-cell function from fasting plasma glucose and insulin concentrations in man. Diabetologia. 1985;28(7):412-9.

11. Zhong Y, Miao Y, Jia WP, Yan H, Wang BY, Jin J. Hyperinsulinemia, insulin resistance and cognitive decline in older cohort. Biomed Environ Sci. 2012;25(1):8-14.

12. Yang WY, Li GW, Xin XY. Prediction of metabolic syndrome with combination of waist-to-hip raio or waist circumference and blood pressure measurements. Chin J Endocrinol Metab. 2005;21(3):227-9.

13. Jia WP, Lu JQ, Chen LF, Tang JL. Insulin resistance, insulin secretion and glucose intolerance in Chinese individuals. Chin J Diabetes. 2000;8(2):67-71.

14. Joint committee for developing Chinese guidelines on prevention and treatment of dyslipidemia in adults. Chinese guidelines on prevention and treatment of dyslipidemia in adults. Chin J Cardiol. 2007;35(5):390-419.

15. World Health Organization(WHO). Obesity: Preventing and managing the global epidemic. Report of a WHO consultation. WHO Tech Rep Ser. 2000;894(i-xii):1-253.

16. Ogden CL, Carroll MD, Kit BK, Flegal KM. Prevalence of obesity and trends in body mass index among US children and adolescents, 1999-2010. JAMA. 2012:307(5):483-90.

17. Finucane MM, Stevens GA, Cowan MJ, Danaei G, Lin JK, Paciorek CJ, et al. National, regional, and global trends in body-mass index since 1980: systematic analysis of health examination surveys and epidemiological studies with 960 country-years and 9.1 million participants. Lancet. 2011:377(9765):557-67.

18. Zhou B, Wu Y, Yang J, Li Y, Zhang H, Zhao L. Overweight is an independent risk factor for cardiovascular disease in Chinese populations. Obes Rev. 2002;3(3):147-56.

19. Hajian-Tilaki $\mathrm{KO}$, Heidari B. Prevalence of obesity, central obesity and the associated factors in urban population aged 20-70 years, in the north of Iran: a population-based study and regression approach. Obes Rev. 2007;8(1):3-10.

20. The World Health Organization Western Pacific Region (WHO-WPR), the International Association for the Study of Obesity (IASO) and the International Obesity Task Force (IOTF). The Asia-Pacific perspective: Redefining obesity and its treatment. Health Communications Australia Pty Ltd.2000:1-55.

21. Nguyen TT, Adair LS, He K, Popkin BM. Optimal cutoff values for overweight: using body mass index to predict incidence of hypertension in 18- to 65-year-old Chinese adults. J Nutr. 2008;138(7):1377-82.

22. Miyawaki T, Hirata M, Moriyama K. Metabolic syndrome in Japanese diagnosed with visceral fat measurement by computed tomography. Proc Japan Acad. 2005:81:471-9.

23. Baik I. Optimal cutoff points of waist circumference for the criteria of abdominal obesity: comparison with the criteria of the International Diabetes Federation. Circ J. 2009:73(11):2068-75.

24. Ko GT, Liu KH, So WY, Tong PC, Ma RC, Ozaki R, et al. Cutoff values for central obesity in Chinese based on mesenteric fat thickness. Clin Nutr. 2009;28(6):679-83.
25. Alberti KG, Eckel RH, Grundy SM, Zimmet PZ, Cleeman Jl, Donato KA, et al. Harmonizing the metabolic syndrome: a joint interim statement of the International Diabetes Federation Task Force on Epidemiology and Prevention; National Heart, Lung, and Blood Institute; American Heart Association; World Heart Federation; International Atherosclerosis Society; and International Association for the Study of Obesity. Circulation. 2009:120(16):1640-5.

26. Janghorbani M, Amini M, Willett WC, Mehdi Gouya M, Delavari A, Alikhani S, et al. First nationwide survey of prevalence of overweight, underweight, and abdominal obesity in Iranian adults. Obesity (Silver Spring). 2007;15(11):2797-808.

27. Hauner $\mathrm{H}$, Bramlage $\mathrm{P}$, Losch $\mathrm{C}$, Jockel KH, Moebus S, Schunkert $\mathrm{H}$, et al. Overweight, obesity and high waist circumference: regional differences in prevalence in primary medical care. Dtsch Arztebl Int. 2008;105(48):827-33.

28. Kamezaki F, Sonoda S, Nakata S, Kashiyama K, Muraoka Y, Okazaki M, et al. Proposed cutoff level of waist circumference in Japanese men: evaluation by homeostasis model assessment of insulin resistance levels. Intern Med. 2012;51(16):2119-24

29. Ho SY, Lam TH, Janus ED. Waist to stature ratio is more strongly associated with cardiovascular risk factors than other simple anthropometric indices. Ann Epidemiol. 2003;13(10):683-91.

30. Yusuf S, Hawken S, Ounpuu S, Bautista L, Franzosi MG, Commerford P, et al. Obesity and the risk of myocardial infarction in 27,000 participants from 52 countries: a case-control study. Lancet. 2005;366(9497):1640-9.

31. Rosenthal AD, Jin F, Shu XO, Yang G, Elasy TA, Chow WH, et al. Body fat distribution and risk of diabetes among Chinese women. Int J Obes Relat Metab Disord. 2004;28(4):594-9.

32. Cameron AJ, Dunstan DW, Owen N, Zimmet PZ, Barr EL, Tonkin AM, et al. Health and mortality consequences of abdominal obesity: evidence from the AusDiab study. Med J Aust. 2009;191(4):202-8.

33. Yin J, Li M, Xu L, Wang Y, Cheng H, Zhao X, et al. Insulin resistance determined by Homeostasis Model Assessment (HOMA) and associations with metabolic syndrome among Chinese children and teenagers. Diabetol Metab Syndr. 2013:5(1):71.

34. Chateau-Degat ML, Dewailly E, Poirier P, Gingras S, Egeland GM. Comparison of diagnostic criteria of the metabolic syndrome in 3 ethnic groups of Canada. Metabolism. 2008;57(11):1526-32.

35. Hsieh SD, Muto T. Metabolic syndrome in Japanese men and women with special reference to the anthropometric criteria for the assessment of obesity: Proposal to use the waist-to-height ratio. Prev Med. 2006;42(2):135-9.

36. Aekplakorn W, Kosulwat V, Suriyawongpaisal P. Obesity indices and cardiovascular risk factors in Thai adults. Int J Obes (Lond). 2006;30(12):1782-90.

37. Liu Y, Tong G, Tong W, Lu L, Qin X. Can body mass index, waist circumference, waist-hip ratio and waist-height ratio predict the presence of multiple metabolic risk factors in Chinese subjects? BMC Public Health. 2011;11:35.

38. Nyamdorj R, Qiao Q, Lam TH, Tuomilehto J, Ho SY, Pitkaniemi J, et al. BMI compared with central obesity indicators in relation to diabetes and hypertension in Asians. Obesity (Silver Spring). 2008;16(7):1622-35.

39. Amato MC, Guarnotta V, Giordano C. Body composition assessment for the definition of cardiometabolic risk. J Endocrinol Invest. 2013:36(7):537-43.

40. Hirani V, Zaninotto P, Primatesta P. Generalised and abdominal obesity and risk of diabetes, hypertension and hypertension-diabetes co-morbidity in England. Public Health Nutr. 2008;11(5):521-7.

41. Cabrera M, Sanchez-Chaparro MA, Valdivielso P, Quevedo-Aguado L, Catalina-Romero C, Fernandez-Labandera C, et al. Prevalence of atherogenic dyslipidemia: association with risk factors and cardiovascular risk in Spanish working population. "ICARIA" study. Atherosclerosis. 2014;235(2):562-9.

42. Ko GT, Chan JC, Chan AW, Wong PT, Hui SS, Tong SD, et al. Low levels of awareness of suboptimal health conditions in a high-risk working population: the "better health for better Hong Kong" health promotion campaign. Int J Behav Med. 2007:14(2):63-9. 